OPEN ACCESS

Edited by:

Mario Alberto Rodriguez, Instituto Politécnico Nacional de México, Mexico

Reviewed by: Sini Skariah,

Weill Cornell Medicine, Qatar Christian Doerig,

RMIT University, Australia Joo Hwan No,

Korea Pasteur Institute, South Korea

*Correspondence: Anne Silvestre

anne.silvestre@inrae.fr Najma Rachidi

najma.rachidi@pasteur.fr

Specialty section: This article was submitted to

Parasite and Host, a section of the journal

Frontiers in Cellular and Infection Microbiology

Received: 30 November 2021 Accepted: 25 January 2022

Published: 17 February 2022

Citation:

Silvestre A, Shintre SS and Rachidi N

(2022) Released Parasite-Derived Kinases as Novel Targets for Antiparasitic Therapies. Front. Cell. Infect. Microbiol. 12:825458. doi: 10.3389/fcimb.2022.825458

\section{Released Parasite-Derived Kinases as Novel Targets for Antiparasitic Therapies}

\author{
Anne Silvestre ${ }^{1 *}$, Sharvani Shrinivas Shintre ${ }^{1,2}$ and Najma Rachidi ${ }^{2 *}$ \\ 1 INRAE, Université de Tours, ISP, Nouzilly, France, 2 Institut Pasteur, Université de Paris and INSERM U1201, Unité de \\ Parasitologie Moléculaire et Signalisation, Paris, France
}

The efficient manipulation of their host cell is an essential feature of intracellular parasites. Most molecular mechanisms governing the subversion of host cell by protozoan parasites involve the release of parasite-derived molecules into the host cell cytoplasm and direct interaction with host proteins. Among these released proteins, kinases are particularly important as they govern the subversion of important host pathways, such as signalling or metabolic pathways. These enzymes, which catalyse the transfer of a phosphate group from ATP onto serine, threonine, tyrosine or histidine residues to covalently modify proteins, are involved in numerous essential biological processes such as cell cycle or transport. Although little is known about the role of most of the released parasite-derived kinases in the host cell, they are examples of kinases hijacking host cellular pathways such as signal transduction or apoptosis, which are essential for immune response evasion as well as parasite survival and development. Here we present the current knowledge on released protozoan kinases and their involvement in host-pathogen interactions. We also highlight the knowledge gaps remaining before considering those kinases - involved in host signalling subversion - as antiparasitic drug targets.

Keywords: excreted kinase, eukaryote, protozoa, signal transduction, antimicrobial therapy

\section{INTRODUCTION}

The efficient manipulation of their host cell is an essential feature of intracellular parasites, which they achieve by secreting effectors to maintain their replicative niche within the host cell and to hijack important host pathways. Among those effectors, kinases have been shown to regulate a wide range of pathways, such as signalling or metabolic pathways. The potential key role of secreted kinases in the subversion of host cell signalling pathways, make them candidates of choice for the development of new antiparasitic treatments, particularly with the growing concern of drug resistance. Targeting secreted effectors may reduce the risk of drug resistance, as any mutation to bypass the drug effect may prevent their extra-parasite role and thus result in high fitness costs for the parasite. Despite their importance, only few parasite-secreted kinases have been studied and their functions in the host cell characterised. We focused on two phylums:

-The Apicomplexa (Alveolata) with Plasmodium spp., Toxoplasma gondii and Eimeria tenella, the causative agents of malaria - transmitted by female anopheles mosquitoes -, toxoplasmosis and coccidiosis, respectively; 
-The kinetoplastids (Euglenozoa) with Leishmania spp., the causative agent of leishmaniasis, transmitted by the bite of a female sand fly and Trypanosoma cruzi, the causative agent of Chagas disease, spread by Triatominae.

In the present mini review, we describe the known mechanisms of parasite effector secretion and compare the secreted kinome from phylogenetically distant intracellular protozoan parasites. We give examples of the host functions of the few studied secreted kinases and highlight the scientific gaps remaining to fully understand host signalling subversion by parasites.

\section{MECHANISMS OF PARASITE EFFECTOR RELEASE/SECRETION}

Parasites release virulence factors either as soluble molecules or inside extracellular vesicles (EVs), leading to the modification of the biological and immune functions of their host cell to ensure their survival (Silverman et al., 2010b; Regev-Rudzki et al., 2013). Apicomplexa and kinetoplastids parasites display different mode of host-parasite interactions due to the specificity of their host cell and their mode of cell entry, which might be partly reflected in the mechanism of parasite protein secretion.

\section{Common to Most Apicomplexa and Kinetoplastids}

Exocytosis, driven by the active transport of secretory vesicles is the eukaryotic conventional secretion system for proteins containing a hydrophobic domain in $\mathrm{N}$-terminal position [Signal Peptide, SP, see (Beer and Wehman, 2017) for an illustrated review]. These protein-containing vesicles traffic from the Golgi apparatus to the plasma membrane, fuse with the plasma membrane to release the secreted proteins in the extracellular environment (Colombo et al., 2014). This secretion system does not account for all the molecules exported by parasites. In Leishmania, 98\% of the secreted proteins lack SP, suggesting the presence of other secretion pathways (Silverman et al., 2008). The second mechanism is unconventional protein secretion (UPS) and refers to proteins either exposed on the cell surface or in the extracellular medium (Balmer and Faso, 2021). The third mechanism is through extracellular vesicles (EVs), lipid-bound vesicles which either bud from the plasma membrane (microvesicles) or are derived from multivesicular bodies that fuse with the plasma membrane (exosomes) (Dlugonska and Gatkowska, 2016; Mathieu et al., 2019; Babatunde et al., 2020) and for more details in mechanisms of secretion see (Teng and Fussenegger, 2021).

\section{Specific to Apicomplexa}

Apicomplexa have developed specific strategies to release proteins into the host cell, which might be the consequence of cell entry by invasion, contrary to phagocytosis or endocytosis for kinetoplastids. Cell invasion requires the fast discharge of microneme and rhoptry proteins (perforins, lipases, proteases, adhesins and kinases) implicated in gliding motility, parasite attachment, formation of the moving junction and the hijacking of host cell pathways, which might not be compatible with the slower release of proteins by the secretory or exosomal pathways (Tomavo et al., 2013; Bisio and Soldati-Favre, 2019). Proteins are targeted to those compartments by conventional SP and specific motifs. Microneme secretion is triggered by signalling events, involving intracellular cyclic nucleotides, calcium level and phosphatidic acid (Dubois and Soldati-Favre, 2019) and is followed by rhoptry secretion (Aquilini et al., 2021). In addition to micronemes and rhoptries, Plasmodium species create, in the host cell cytoplasm, a network of membranous structures of parasite origin, called Maurer's clefts. These structures are attached to the host cytoskeleton and act as extracellular secretory and trafficking organelles for the parasite (Lanzer et al., 2006) but little is known about their biogenesis and functions. Finally, some proteins contain PEXEL motifs in Plasmodium (Marti et al., 2004) and TEXEL motifs in Toxoplasma (Coffey et al., 2015), which are required for their release via exporters located on the parasitophorous vacuole membrane (PVM). The PVM derives from the host cell membrane and is modified by incorporation of parasite proteins, to avoid phagolysosome fusion (de Koning-Ward et al., 2009; Marino et al., 2018). This pathway corresponds to the default constitutive secretion pathway (Venugopal et al., 2020).

\section{EXOPROTEOMES OF APICOMPLEXA AND TRYPANOSOMATIDS}

There is a growing body of data on the exo-proteome, whatever the mechanism of secretion used by parasites. It contains a range of protein classes including proteases, kinases, membrane proteins, heat shock proteins or nucleic acids, which induce specific modifications in the host cell (Montaner et al., 2014). Only little is known about the mechanisms involved in cargo selection of these EVs. Leishmania HSP100 has a strong impact on protein cargo composition: its deletion affects the immune status of the host cell and parasite survival (Silverman et al., 2011). The EV composition is sensitive to environmental cues (Hassani et al., 2011) and might contribute to the spread of drug resistance (Douanne et al., 2020). EVs have an essential role during infection (Torrecilhas et al., 2020); co-egestion of Leishmania and its EVs by the sand fly induces the inflammatory recruitment of neutrophils and macrophages (Atayde et al., 2015). EVs are involved in immune evasion; T. cruzi exosomes aggravate the infection due to severe inflammatory response and increase the parasite burden (Trocoli Torrecilhas et al., 2009). Several vesicular virulence factors from T. cruzi have been involved in host invasion, intracellular parasite proliferation or immune evasion (Costa et al., 2016). For Apicomplexa, T. gondii exosomes has been 
shown to activate a pro-inflammatory immune response ( $\mathrm{Li}$ et al., 2018), and small non-coding RNAs and genomic DNA contained in EVs released from RBC infected by $P$. falciparum are detected by the STING pathway, favouring parasite survival (Sisquella et al., 2017). However, accessing parasite-derived EVs is challenging, as apicomplexans parasites cannot be cultured without their host cell, thus most of the data available on their exo-proteome is in fact from host-derived EVs.

\section{SECRETED/EXCRETED PARASITE KINASES}

Phosphorylation, an essential reversible post-translational modification, affects every cellular process (Ardito et al., 2017). It acts as a molecular switch for many biological processes, including signal transduction networks in response to extracellular stimuli. Phosphorylation is catalysed by kinases, which transfers phosphate from ATP onto proteins, sugars or lipids. Upon phosphorylation, the chemical properties, conformation, localisation and/or activity of the molecule change, inducing rapid downstream effects in the cell (Hunter and Sibley, 2012). To survive, intracellular pathogens need to exploit the host pathways either to fulfil their needs for proliferation or to inhibit the host defence responses. Targeting the phospho-proteome of the host is the fastest way to subvert a large repertoire of biological and immune processes (RegevRudzki et al., 2013; Carrera-Bravo et al., 2021).

\section{Kinases}

Most studies on kinases refers to protein kinases. Protozoan parasite kinomes contain orthologues for 6 of the 8 groups of conventional eukaryotic PKs (ePK): AGC, CAMK, CK1, CMGC, STE and TKL) and some "others" that share ePK folding but cannot be assigned to any major ePK group from humans (Peixoto et al., 2010; Talevich et al., 2011). One additional group Kinetoplastids, NEK family, is involved in cell cycle and cytoskeletal functions. Apicomplexa contains also specific ePK (FIKK, ROPK and WNG), differentially conserved and/or duplicated within Apicomplexa parasite phylum (Ward et al., 2004; Beraki et al., 2019). While only one FIKK gene was identified in coccidia (Toxoplasma, Eimeria) and in most Plasmodium species, this group is expanded in $P$. falciparum with 20 kinases and in several Plasmodium sp. infecting apes (Adderley et al., 2021). Most of the rhoptry proteins are kinases (ROPK), either active, inactive (lacking a complete catalytic triad) or non-canonical (active with differences in conserved residues) (Bradley et al., 2005). Finally, very recently, a new group of four kinases specific to coccidia, and missing the typical glycine loop was identified (WNG1-3 and BPK1) (Beraki et al., 2019). BPK1 is associated with bradyzoite cyst wall, with a crucial role in in vivo cyst infectivity (Boothroyd, 2013; Buchholz et al., 2013). In Eimeria, two WNGs are predicted, but their functions remain unknown. To date, only TgWNG1 has been functionally characterized: it is involved in the phosphorylation of GRA, a family of effectors stored in dense granule vesicles and secreted to develop the intra-vacuolar network, implicated in survival of parasite. Although as important as protein kinases, there are no comprehensive studies available on carbohydrate, lipid, nucleoside or other kinases, but only individual publications (Pereira et al., 2011).

\section{Host Functions of Secreted Kinases}

Proteomic characterisation of parasite exo-proteomes revealed the presence of only few kinases, mostly involved in pathways such as glycolysis, cellular energy homeostasis or cell signalling (Table 1). While in Apicomplexa most secreted kinases target proteins, in Leishmania and T. cruzi, more than half of the kinases target nucleosides, carbohydrates or lipids (Figure 1). Eight kinases are released by both kinetoplastids and Apicomplexa (Table 1, bold), suggesting that host subversion mediated by those kinases might be conserved between parasites. Five kinases might be kinetoplastid-specific (Table 1, italic) and only one might be Apicomplexa-specific (CDPKs, Table 1, underlined). This low number of specific kinases may be due to the scarce proteomic data available for these parasites.

\section{Glycolytic Kinases}

Glycolytic kinases are located in the glycosomes of kinetoplastids and in the cytosol and the apicoplast of Apicomplexa (Saito et al., 2002; Fleige et al., 2007). They regulate glycolysis but have additional biological functions, as moonlighting proteins. For instance, Leishmania hexokinase, a glycolytic enzyme, also acts as a haemoglobin $(\mathrm{Hb})$ receptor, allowing $\mathrm{Hb}$ internalisation (Krishnamurthy et al., 2005). L. donovani aldolase, another glycolytic enzyme, interacts with and activates the host SHP-1 (protein tyrosine phosphatase). SHP-1 inhibits M1 macrophage polarization, creating a more favourable environment for Leishmania (Nandan et al., 2007; Garg et al., 2020). Although important in number, nothing is known about the host functions of glycolytic kinases, but their release by most the parasites suggest important roles in the host cell.

\section{Nucleoside Diphosphate Kinase (Ndk)}

Ndk catalyses the transfer of phosphate from nucleoside triphosphate (NTP) to nucleoside diphosphate (NDP) to maintain ATP cellular homeostasis (Kolli et al., 2008). This kinase also plays roles in the regulation of gene transcription, DNA repair, differentiation and apoptosis (Yu et al., 2017). Ndk seems important for drug resistance in T. cruzi and in Leishmania, its overexpression leads to a decrease sensitivity to antimony $\left(\mathrm{Sb}^{\mathrm{III}}\right)$ (Moreira and Murta, 2016); for DNA damage responses in T. cruzi (Miranda et al., 2008); and for parasite replication in T. gondii (Lykins et al., 2018). In these parasites, Ndk is released in EVs (Silverman et al., 2008; Silverman et al., 2010a; Bayer-Santos et al., 2013; Lee et al., 2014; Brossas et al., 2017). In Leishmania, the release of ndk prevents extracellular ATP (eATP)-mediated cytolysis of infected macrophages (Kolli et al., 2008). eATP, a signal nucleotide, binds to and 
TABLE 1 | Kinases secreted by protozoan parasites.

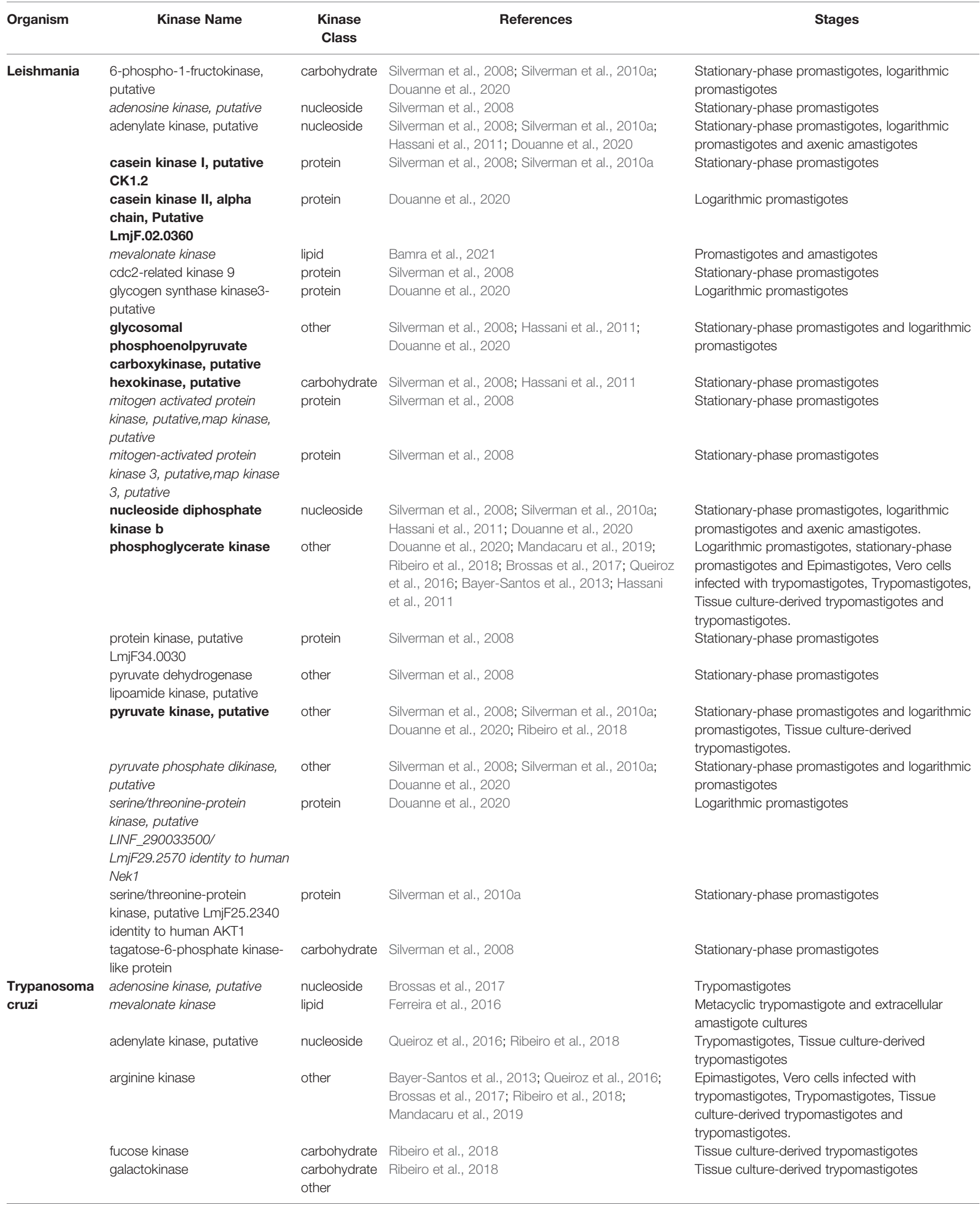


TABLE 1 | Continued

\begin{tabular}{|c|c|c|c|c|}
\hline Organism & Kinase Name & $\begin{array}{l}\text { Kinase } \\
\text { Class }\end{array}$ & References & Stages \\
\hline & \multicolumn{2}{|l|}{$\begin{array}{l}\text { glycosomal } \\
\text { phosphoenolpyruvate } \\
\text { carboxykinase, putative }\end{array}$} & $\begin{array}{l}\text { Queiroz et al., 2016; Ribeiro et al., 2018; } \\
\text { Mandacaru et al., } 2019\end{array}$ & $\begin{array}{l}\text { Trypomastigotes, Tissue culture-derived } \\
\text { trypomastigotes and trypomastigotes. }\end{array}$ \\
\hline & hexokinase & \multirow{2}{*}{$\begin{array}{l}\text { carbohydrate } \\
\text { protein }\end{array}$} & Bayer-Santos et al., 2013, Mandacaru et al., 2019 & Epimastigotes and trypomastigotes. \\
\hline & $\begin{array}{l}\text { mitogen-activated protein } \\
\text { kinase, putative }\end{array}$ & & $\begin{array}{l}\text { Bayer-Santos et al., 2013; Brossas et al., 2017; } \\
\text { Ribeiro et al., } 2018\end{array}$ & $\begin{array}{l}\text { Epimastigotes, Vero cells infected with } \\
\text { trypomastigotes, Tissue culture-derived } \\
\text { trypomastigotes }\end{array}$ \\
\hline & \multirow{2}{*}{$\begin{array}{l}\text { NIMA-related kinase, putative } \\
\text { nucleoside diphosphate } \\
\text { kinase B }\end{array}$} & \multirow{2}{*}{$\begin{array}{l}\text { protein } \\
\text { nucleoside }\end{array}$} & Queiroz et al., 2016 & Trypomastigotes \\
\hline & & & $\begin{array}{l}\text { Bayer-Santos et al., 2013; Brossas et al., 2017; } \\
\text { Queiroz et al., 2016; Ribeiro et al., 2018; } \\
\text { Mandacaru et al., } 2019\end{array}$ & $\begin{array}{l}\text { Epimastigotes, Vero cells infected with } \\
\text { trypomastigotes, Trypomastigotes, Tissue } \\
\text { culture-derived trypomastigotes and } \\
\text { trypomastigotes. }\end{array}$ \\
\hline & \multirow{5}{*}{$\begin{array}{l}\text { phosphatidylinositol-3-Kinase } \\
\text { Protein kinase } \\
\text { Tc00.1047053506211.210 } \\
\text { MAPKKK identity to human } \\
\text { PAK1/PAK3 }\end{array}$} & \multirow{5}{*}{$\begin{array}{l}\text { lipid } \\
\text { protein }\end{array}$} & \multirow{5}{*}{$\begin{array}{l}\text { Bayer-Santos et al., } 2013 \\
\text { Ribeiro et al., } 2018\end{array}$} & \multirow{5}{*}{$\begin{array}{l}\text { Epimastigotes } \\
\text { Tissue culture-derived trypomastigotes }\end{array}$} \\
\hline & & & & \\
\hline & & & & \\
\hline & & & & \\
\hline & & & & \\
\hline & Protein kinase, putative & \multirow[t]{2}{*}{ protein } & \multirow[t]{2}{*}{ Brossas et al., 2017} & \multirow[t]{2}{*}{ Vero cells infected with trypomastigotes } \\
\hline & $\begin{array}{l}\text { TcCLB.508641.170 identity to } \\
\text { human PKC theta }\end{array}$ & & & \\
\hline & $\begin{array}{l}\text { protein kinase-A catalytic } \\
\text { subunit }\end{array}$ & protein & Queiroz et al., 2016 & Trypomastigotes \\
\hline & pyridoxal kinase, putative & other & Queiroz et al., 2016; Ribeiro et al., 2018 & $\begin{array}{l}\text { Trypomastigotes, Tissue culture-derived } \\
\text { trypomastigotes }\end{array}$ \\
\hline & pyruvate kinase 2 , putative & other & Queiroz et al., 2016 & Trypomastigotes \\
\hline & pyruvate phosphate dikinase 2 & other & Queiroz et al., 2016 & Trypomastigotes \\
\hline & pyruvate phosphate dikinase 1 & other & Bayer-Santos et al., 2013; Ribeiro et al., 2018 & $\begin{array}{l}\text { Epimastigotes, Tissue culture-derived } \\
\text { trypomastigotes }\end{array}$ \\
\hline & $\begin{array}{l}\text { serine/threonine protein kinase } \\
T C C L B .508153 .400 /\end{array}$ & protein & Bayer-Santos et al., 2013; Ribeiro et al., 2018 & $\begin{array}{l}\text { Epimastigotes, Tissue culture-derived } \\
\text { trypomastigotes }\end{array}$ \\
\hline & $\begin{array}{l}\text { TCSYLVIO_004423 identity to } \\
\text { human Nek1 }\end{array}$ & & & trypomastigotes \\
\hline & $\begin{array}{l}\text { serine/threonine-protein kinase } \\
\text { 10, putative }\end{array}$ & protein & Queiroz et al., 2016 & Trypomastigotes \\
\hline & $\begin{array}{l}\text { TcCLB.506401.110 identity to } \\
\text { human STK10 }\end{array}$ & & & \\
\hline \multirow[t]{15}{*}{ Plasmodium } & $\begin{array}{l}\text { Camk2d calcium/ } \\
\text { calmodulin_dependent protein } \\
\text { kinase II_delta isoform } 1\end{array}$ & protein & Martin-Jaular et al., 2011 & Trophozoite P. yoelii infected reticulocyte \\
\hline & $\begin{array}{l}\text { Camk2d Isoform } 1 \text { of Calcium/ } \\
\text { calmodulin_dependent protein } \\
\text { kinase type II delta chain }\end{array}$ & protein & Martin-Jaular et al., 2011 & Trophozoite P. yoelii infected reticulocyte \\
\hline & $\begin{array}{l}\text { Camk2d Isoform } 2 \text { of Calcium/ } \\
\text { calmodulin_dependent protein } \\
\text { kinase type II delta chain }\end{array}$ & protein & Martin-Jaular et al., 2011 & Trophozoite P. yoelii infected reticulocyte \\
\hline & $\begin{array}{l}\text { Camk2d Isoform } 3 \text { of Calcium/ } \\
\text { calmodulin_dependent protein } \\
\text { kinase type II delta chain }\end{array}$ & protein & Martin-Jaular et al., 2011 & Trophozoite P. yoelii infected reticulocyte \\
\hline & $\begin{array}{l}\text { Camk2d Isoform } 4 \text { of Calcium/ } \\
\text { calmodulin_dependent protein } \\
\text { kinase type II delta chain }\end{array}$ & protein & Martin-Jaular et al., 2011 & Trophozoite P. yoelii infected reticulocyte \\
\hline & $\begin{array}{l}\text { casein kinase } 2 \text {, alpha } \\
\text { subunit }\end{array}$ & protein & Abdi et al., 2017 & Trophozoite P. falciparum infected erythrocyte \\
\hline & diacyl glycerol kinase & lipid & Gualdron-Lopez et al., 2018 & Trophozoite $P$. vivax infected erythrocyte \\
\hline & FIKK10.1 & protein & Hiller et al., 2004 & Trophozoite $P$. falciparum infected erythrocyte \\
\hline & FIKK13 & protein & Hiller et al., 2004 & Trophozoite $P$. falciparum infected erythrocyte \\
\hline & FIKK14 & protein & Hiller et al., 2004 & Trophozoite $P$. falciparum infected erythrocyte \\
\hline & FIKK1 & protein & Hiller et al., 2004 & Trophozoite $P$. falciparum infected erythrocyte \\
\hline & FIKK4.1 & protein & Hiller et al., 2004 & Trophozoite P. falciparum infected erythrocyte \\
\hline & FIKK4.2 & protein & Hiller et al., 2004 & Trophozoite $P$. falciparum infected erythrocyte \\
\hline & FIKK7.1 & protein & Hiller et al., 2004 & Trophozoite $P$. falciparum infected erythrocyte \\
\hline & FIKK9.1 & protein & Hiller et al., 2004 & Trophozoite $P$. falciparum infected erythrocyte \\
\hline
\end{tabular}


TABLE 1 | Continued

\begin{tabular}{|c|c|c|c|c|}
\hline Organism & Kinase Name & $\begin{array}{l}\text { Kinase } \\
\text { Class }\end{array}$ & References & Stages \\
\hline & FIKK9.3 & protein & Hiller et al., 2004 & Trophozoite $P$. falciparum infected erythrocyte \\
\hline & FIKK9.6 & protein & Hiller et al., 2004 & Trophozoite $P$. falciparum infected erythrocyte \\
\hline & FIKK10.2 & protein & Hiller et al., 2004 & Trophozoite $P$. falciparum infected erythrocyte \\
\hline & FIKK11 & protein & Hiller et al., 2004 & Trophozoite $P$. falciparum infected erythrocyte \\
\hline & FIKK12 & protein & Hiller et al., 2004 & Trophozoite $P$. falciparum infected erythrocyte \\
\hline & $\begin{array}{l}\text { pacsin2 Protein kinase } \mathrm{C} \text { and } \\
\text { casein kinase substrate in } \\
\text { neurons protein } 2\end{array}$ & protein & Martin-Jaular et al., 2011 & Trophozoite P. yoelii infected reticulocyte \\
\hline & $\begin{array}{l}\text { phosphatidylinositol 4-kinase, } \\
\text { putative }\end{array}$ & lipid & Abdi et al., 2017 & Trophozoite P. falciparum infected erythrocyte \\
\hline & phosphoglycerate kinase & other & Mantel et al., 2013; Abdi et al., 2017 & Trophozoite P. falciparum infected erythrocyte \\
\hline & $\begin{array}{l}\text { pseudo protein kinase 1, } \\
\text { putative PF3D7_0321400 }\end{array}$ & protein & Abdi et al., 2017 & Trophozoite $P$. falciparum infected erythrocyte \\
\hline & pyruvate kinase & other & Vincensini et al., 2005; Mantel et al., 2013 & Trophozoite P. falciparum infected erythrocyte \\
\hline & $\begin{array}{l}\text { serine/threonine protein kinase, } \\
\text { putative PF3D7_1441300 }\end{array}$ & protein & Abdi et al., 2017 & Trophozoite $P$. falciparum infected erythrocyte \\
\hline & $\underline{\text { calcium-dependent protein }}$ & protein & Lal et al., 2009 & Purified microneme organelle \\
\hline & $\begin{array}{l}\text { calcium-dependent protein } \\
\text { kinase CDPK4 }\end{array}$ & protein & Lal et al., 2009 & Purified microneme organelle \\
\hline & adenylate kinase & nucleoside & Vincensini et al., 2005 & Trophozoite $P$. falciparum infected erythrocyte \\
\hline \multirow[t]{27}{*}{ Toxoplasma } & $\begin{array}{l}\text { calcium-dependent protein } \\
\text { kinase CDPK1 }\end{array}$ & protein & Wowk et al., 2017; Ramirez-Flores et al., 2019 & $\begin{array}{l}\text { Tachyzoite } T \text {. gondii infected human foreskin } \\
\text { fibroblast, Acellular tachyzoites }\end{array}$ \\
\hline & $\begin{array}{l}\text { calcium-dependent protein } \\
\text { kinase CDPK2A }\end{array}$ & protein & Wowk et al., 2017 & $\begin{array}{l}\text { Tachyzoite } T \text {. gondii infected human foreskin } \\
\text { fibroblast }\end{array}$ \\
\hline & $\begin{array}{l}\text { calcium-dependent protein } \\
\text { kinase CDPK3 }\end{array}$ & protein & Wowk et al., 2017; Ramirez-Flores et al., 2019 & $\begin{array}{l}\text { Tachyzoite T. gondii infected human foreskin } \\
\text { fibroblast, Acellular tachyzoites }\end{array}$ \\
\hline & casein kinase I & protein & Wowk et al., 2017 & $\begin{array}{l}\text { Tachyzoite } T \text {. gondii infected human foreskin } \\
\text { fibroblast }\end{array}$ \\
\hline & CMGC kinase, CK2 family & protein & Wowk et al., 2017; Ramirez-Flores et al., 2019 & $\begin{array}{l}\text { Tachyzoite } T \text {. gondii infected human foreskin } \\
\text { fibroblast, Acellular tachyzoites }\end{array}$ \\
\hline & hexokinase & carbohydrate & Wowk et al., 2017; Ramirez-Flores et al., 2019 & $\begin{array}{l}\text { Tachyzoite } T \text {. gondii infected human foreskin } \\
\text { fibroblast, Acellular tachyzoites }\end{array}$ \\
\hline & $\begin{array}{l}\text { nucleoside diphosphate } \\
\text { kinase }\end{array}$ & nucleoside & Lee et al., 2014 & Acellular tachyzoites \\
\hline & $\begin{array}{l}\text { phosphoenolpyruvate- } \\
\text { carboxykinase I }\end{array}$ & other & Wowk et al., 2017 & $\begin{array}{l}\text { Tachyzoite } T \text {. gondii infected human foreskin } \\
\text { fibroblast }\end{array}$ \\
\hline & phosphofructokinase PFKII & carbohydrate & Wowk et al., 2017 & $\begin{array}{l}\text { Tachyzoite } T \text {. gondii infected human foreskin } \\
\text { fibroblast }\end{array}$ \\
\hline & phosphoglycerate kinase & other & Wowk et al., 2017 & $\begin{array}{l}\text { Tachyzoite } T \text {. gondii infected human foreskin } \\
\text { fibroblast }\end{array}$ \\
\hline & pyruvate kinase & other & Wowk et al., 2017 & $\begin{array}{l}\text { Tachyzoite } T \text {. gondii infected human foreskin } \\
\text { fibroblast }\end{array}$ \\
\hline & $\begin{array}{l}\text { rhoptry kinase family protein } \\
\text { ROP39 }\end{array}$ & protein & Wowk et al., 2017 & $\begin{array}{l}\text { Tachyzoite } T \text {. gondii infected human foreskin } \\
\text { fibroblast }\end{array}$ \\
\hline & selenide, water dikinase & other & Wowk et al., 2017 & $\begin{array}{l}\text { Tachyzoite } T \text {. gondii infected human foreskin } \\
\text { fibroblast }\end{array}$ \\
\hline & ROP2 - PK-like & protein & Bradley et al., 2005 & Purified rhoptry organelle \\
\hline & ROP4 - PK-like & protein & Bradley et al., 2005 & Purified rhoptry organelle \\
\hline & ROP5 - PK-like & protein & Bradley et al., 2005 & Purified rhoptry organelle \\
\hline & ROP8 - PK-like & protein & Bradley et al., 2005 & Purified rhoptry organelle \\
\hline & ROP11 - PK-like & protein & Bradley et al., 2005 & Purified rhoptry organelle \\
\hline & ROP16 - PK-like & protein & Bradley et al., 2005 & Purified rhoptry organelle \\
\hline & ROP17 - PK-like & protein & Bradley et al., 2005 & Purified rhoptry organelle \\
\hline & ROP18 - PK-like & protein & Bradley et al., 2005 & Purified rhoptry organelle \\
\hline & ROP38 - PK-like & protein & Bradley et al., 2005 & Purified rhoptry organelle \\
\hline & WNG1 (With-No-Gly-Loop) & protein & Beraki et al., 2019 & Bradyzoite \\
\hline & WNG2 & protein & Beraki et al., 2019 & Bradyzoite \\
\hline & WNG3 & protein & Beraki et al., 2019 & Bradyzoite \\
\hline & BPK1 bradyzoite & protein & Buchholz et al., 2013 & Bradyzoite \\
\hline & pseudokinase 1 & & & \\
\hline Eimeria $^{a}$ & pyruvate kinase & other & Labbé et al., 2006 & Schizont from in vitro infected cells \\
\hline
\end{tabular}


TABLE 1 | Continued

\begin{tabular}{|c|c|c|c|c|}
\hline Organism & Kinase Name & $\begin{array}{l}\text { Kinase } \\
\text { Class }\end{array}$ & References & Stages \\
\hline & hexokinase & carbohydrate & Sun et al., 2016 & Sporozoite from in vitro infected cells \\
\hline & $\frac{\text { calcium-dependent protein }}{\underline{\text { kinase CDPK1 }}}$ & protein & Dunn et al., 1996 & Sporozoite from in vitro infected cells \\
\hline & $\begin{array}{l}\text { calcium-dependent protein } \\
\text { kinase CDPK2 }\end{array}$ & protein & Dunn et al., 1996 & Sporozoite from in vitro infected cells \\
\hline & $\begin{array}{l}\text { calcium-dependent protein } \\
\underline{\text { kinase CDPK3 }}\end{array}$ & protein & Han et al., 2013 & $\begin{array}{l}\text { Sporozoite and schizont from in vitro infected } \\
\text { cells }\end{array}$ \\
\hline & $\begin{array}{l}\text { calcium-dependent protein } \\
\text { kinase CDPK4 }\end{array}$ & protein & Wang et al., $2016 \mathrm{a}$ & $\begin{array}{l}\text { Sporozoite and merozoite from in vitro infected } \\
\text { cells }\end{array}$ \\
\hline & $\overline{\text { ETH_00000075 }}$ & protein & Oakes et al., 2013 & Purified rhoptry organelle \\
\hline & ETH_00005190 - EtROP1 & protein & Oakes et al., 2013 & Purified rhoptry organelle \\
\hline & ETH_00005400 & protein & Oakes et al., 2013 & Purified rhoptry organelle \\
\hline & ETH_00005840 & protein & Oakes et al., 2013 & Purified rhoptry organelle \\
\hline & ETH_00005905 & protein & Oakes et al., 2013 & Purified rhoptry organelle \\
\hline & ETH_00020620 & protein & Oakes et al., 2013 & Purified rhoptry organelle \\
\hline & ETH_00026495 & protein & Oakes et al., 2013 & Purified rhoptry organelle \\
\hline & ETH_00027695 & protein & Oakes et al., 2013 & Purified rhoptry organelle \\
\hline & ETH_00027700 & protein & Oakes et al., 2013 & Purified rhoptry organelle \\
\hline & ETH_00027855 & protein & Oakes et al., 2013 & Purified rhoptry organelle \\
\hline & ETH_00028765 & protein & Oakes et al., 2013 & Purified rhoptry organelle \\
\hline & WNG 1 , predicted & protein & Beraki et al., 2019 & $N D^{\mathrm{b}}$ \\
\hline & WNG4, predicted & protein & Beraki et al., 2019 & $N D^{b}$ \\
\hline
\end{tabular}

aSecreted kinases listed for Eimeria are underestimated, due to a lack of datasets. Eimeria pyruvate kinase (Labbé et al., 2006), hexokinase (Sun et al., 2016) and CDPK (Dunn et al., 1996; Han et al., 2013; Wang et al., 2016a) are secreted by an unknown mechanism.

${ }^{b}$ Not determined.

Kinase class refers to the kinase substrate. Kinases common to kinetoplastids and Apicomplexa are indicated in bold, kinases specific to kinetoplastids or to Apicomplexa are indicated in italic or underlined, respectively. Based on experimental procedures of cited references for Apicomplexa, kinases from organelles are secreted in the host cell cytoplasm, not in the extracellular medium. To the author knowledge, only P. falciparum TKL2 and PfCK1 were detected in extracellular medium and at the erythrocyte membrane (Abdi et al., 2013) and maybe associated to immunomodulatory functions. Most of the secreted proteins of Kinetoplastids are released inside the host cell. Ndk and AK seem to be secreted in the extracellular environment of the host cell due to their role. Limitations concerning secretome preparation and characterization have been reviewed (Severino et al., 2013).

activates the $\mathrm{P} 2 \mathrm{X} 7$ receptor, which is responsible for the pore formation in the membrane of macrophages, resulting in cell death (Kolli et al., 2008; Kulkarni et al., 2019). By transferring phosphate from ATP to NDP, Ndk decreases eATP, thus prevents ATP-induced changes in mitochondrial permeability of macrophages. Furthermore, Ndk participates in the host purine salvage by protozoan parasites by utilizing eATP to produce other NTPs such as GTP (Kolli et al., 2008) These functions might be conserved in T. cruzi and T. gondii, which also release $\mathrm{Ndk}$.

\section{Casein Kinase 1}

Casein kinase $1(\mathrm{CK} 1)$ is a serine/threonine protein kinase that regulates a wide range of biological processes (Xu et al., 2019; Rachidi et al., 2021). In Leishmania, three paralogs are released: L-CK1.4 through the classical secretory pathway, L-CK1.5 and LCK1.2 via exosomes (Table 1). Nothing is known about the role of these paralogs in the host cell, except for L-CK1.2. This kinase phosphorylates human IFNAR1 receptor, physiological target of human $\mathrm{CK} 1 \alpha$, to promote its ubiquitination and subsequent degradation, leading to the attenuation of the cellular response to interferon $\alpha / \beta$ (Liu et al., 2009). Recently additional host proteins phosphorylated by L-CK1.2 were identified (Smirlis et al., 2022). Several pathways, such as apoptosis, actin skeleton organisation or RNA processing were shown to be potentially regulated by L-CK1.2, which corresponds to pathways altered during Leishmania infection (Smirlis et al., 2020). These findings suggest that L-CK1.2 might replace human CK1 and phosphorylate host proteins to modify the immune status of the host cell. Among the three CK1 isoforms encoded by $T$. gondii, only CK1 $\alpha$ is secreted in EVs (Donald et al., 2005; Wowk et al., 2017; Rachidi et al., 2021). In contrast to its kinetoplastid orthologs, it is still unclear whether $\operatorname{TgCK} 1 \alpha$ is essential for $T$. gondii survival or what are its functions in the host cell. However, TgCK1 $\alpha$ is not a candidate drug target, as its deletion increases T. gondii virulence (Wang et al., 2016b). Finally, P. falciparum expresses only one CK1, which is secreted by potentially hijacking the trafficking system of the host cell (Dorin-Semblat et al., 2015). Ten PfCK1-interacting host proteins were identified and are involved in various pathways, such as post-translational modifications, translation and protein trafficking/export (Batty et al., 2020).

\section{Adenylate Kinase (AK)}

AK catalyses the transfer of a phosphate group from ATP to AMP to generate two ADPs. It regulates homeostasis of adenine nucleotides and plays an important role in the regulation of the energy metabolism. AK has been detected in the exo-proteome of Leishmania and T. cruzi (Table 1). Recent data from L. donovani, suggests that AK2a prevents ATP-mediated cytolysis of macrophages, similarly to Ndk (Kulkarni et al., 2019). 

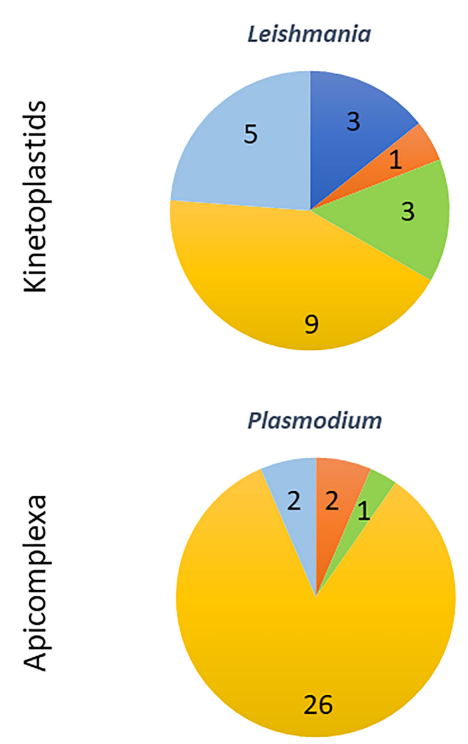
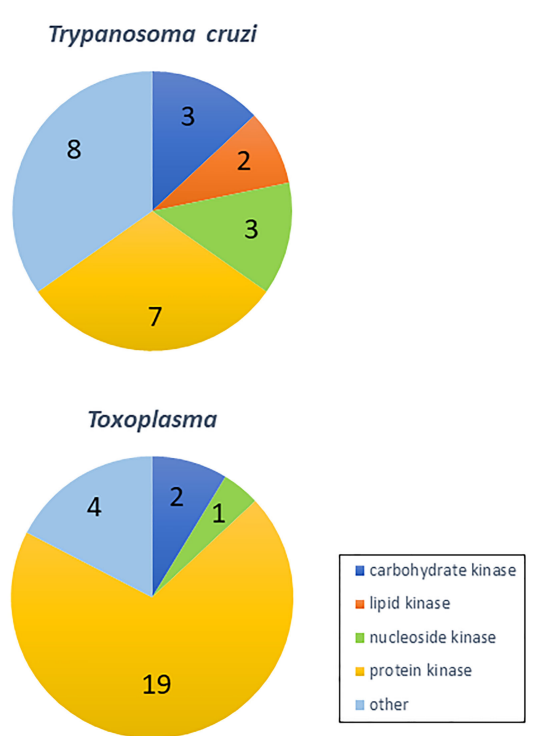

FIGURE 1 | Proportion and number of kinases classes according to their substrates, identified in secretome of Kinetoplastids (Leishmania and Trypanozoma) and Apicomplexa (Toxoplasma and Plasmodium).

\section{Mevalonate Kinase}

L. donovani Mevalonate kinase (MVK) is a glycosomal enzyme, secreted by the parasite via a non-classical secretion pathway (Bamra et al., 2021). MVK catalyses the phosphorylation of mevalonic acid into mevalonate-5-phosphate, which is part of the cholesterol biosynthesis pathway. Macrophage infection with L. donovani over-expressing MVK leads to an increase in parasite internalisation. During extracellular amastigotes invasion, T. cruzi MVK induces the phosphorylation of host Src/FAK, involved in cytoskeleton remodelling of the host (Ferreira et al., 2016), and the phosphorylation of the host P38 and ERK leading to cytoskeleton and microfilament remodelling, which favour parasite internalisation. Moreover, LdMVK is an immunosuppressor, which favours anti-inflammatory cytokines through ERK1/2, increasing parasite survival (Bamra et al., 2021).

\section{FIKKs}

The 18 FIKKs secreted by $P$. falciparum, display an important non-redundant role in cytoskeletal connections, nutrients permeability and ubiquitination of RBC proteins, as shown by the phosphoproteomic profile of their systematic invalidated mutants (Davies et al., 2020). For instance, FIKK4.1 and FIKK4.2 are involved in cytoadhesion of the RBC to the vascular endothelium, by regulating the number/size of knobs formed on the RBC membrane (Kats et al., 2014). FIKK4.1, FIKK7.1 and FIKK12 phosphorylate host cell cytoskeleton proteins, thus modifying RBC rigidity (Nunes et al., 2010; Brandt and Bailey, 2013). Finally, FIKK9.1, FIKK10.1 and FIKK10.2, exported via Maurer's clefts, are essential for parasite survival (Siddiqui et al., 2020).

\section{ROPKs}

ROPK, secreted from the rhoptries, are involved in host-pathogen interaction. Although not all ROPK are functionally characterized, a systematic and targeted T. gondii ROPK knockout screen (Fox et al., 2016) highlighted the role of 20 ROPKs in the establishment of a chronic infection. After their secretion in the host cell cytoplasm, TgROP5, TgROP17 and TgROP18 form a complex on the cytosolic side of the PVM (Etheridge et al., 2014). TgROP5 binds immune-related GTPases (IRG) to decrease their polymerisation rate (Behnke et al., 2012). IRG are then phosphorylated by TgROP18, to prevent their recruitment to the PVM and preserve it (Fleckenstein et al., 2012). Additionally, TgROP17 is also involved in GRA translocation through the PVM, in association with the MYR complex (Panas et al., 2019). TgROP16 (Saeij et al., 2006), TgROP17 (Drewry et al., 2019), TgROP18 (Fentress and Sibley, 2011) and TgROP38 (Peixoto et al., 2010) are known to interfere with and regulate host pathways such as immune response and apoptosis. TgROP16 is localized to the host cell nucleus after invasion (Ong et al., 2010), phosphorylates signal transducer and activator of transcription STAT6 and STAT3 (Yamamoto et al., 2009; Butcher et al., 2011) to bypass the protective immune-response of the host cell. In E. tenella, among 28 ROPKs differentially expressed during the life-cycle (Ribeiro E Silva et al., 2021), only EtROP1 has been functionally characterised (Diallo et al., 2019). It interacts with host $\mathrm{p} 53$, to inhibit host cell apoptosis and induce G0/G1 cell cycle arrest. Interestingly, EtROP1 kinase activity is only required for cell cycle arrest, supporting the hypothesis of an additional kinase that would be responsible for p53 phosphorylation. ROPK inhibitors may offer new therapeutic treatments to control coccidiosis (Simpson et al., 2016). 


\section{CONCLUDING REMARKS}

Released divergent kinases that alter host signalling pathways are interesting as they co-evolve with their host targets to insure their proper function within the host and are thus less prone to mutations that would lead to drug resistance. Some compounds that target those secreted kinases have already been identified. P. falciparum Pyruvate Kinase is efficiently targeted by antimalarial drugs, such as LZ1 (Fang et al., 2019) or suramin, which also targets trypanosomatids Pyruvate Kinase (Zhong et al., 2020). L-CK1.2 has been validated as a drug target and several compounds with anti-leishmanial activity have been identified, for review see (Rachidi et al., 2021). The similarity between PfCK1 and L-CK1.2 suggests that it might also be a good antimalarial drug target. Given the expanse of their effects on the host cell, understanding the roles that kinases secreted by

\section{REFERENCES}

Abdi, A. I., Carvalho, T. G., Wilkes, J. M., and Doerig, C. (2013). A Secreted Plasmodium Falciparum Kinase Reveals a Signature Motif for Classification of Tyrosine Kinase-Like Kinases. Microbiology-Sgm 159, 2533-2547. doi: 10.1099/mic.0.070409-0

Abdi, A. I., Yu, L., Goulding, D., Rono, M. K., Bejon, P., and Choudhary, J. (2017). Proteomic Analysis of Extracellular Vesicles From a Plasmodium Falciparum Kenyan Clinical Isolate Defines a Core Parasite Secretome. Wellcome Open Res. 2, 50. doi: 10.12688/wellcomeopenres.11910.2

Adderley, J., Williamson, T., and Doerig, C. (2021). Parasite and Host Erythrocyte Kinomics of Plasmodium Infection. Trends Parasitol. 37 (6), 508-524. doi: $10.1016 /$ j.pt.2021.01.002

Aquilini, E., Cova, M. M., Mageswaran, S. K., Dos Santos Pacheco, N., Sparvoli, D., Penarete-Vargas, D. M., et al. (2021). An Alveolata Secretory Machinery Adapted to Parasite Host Cell Invasion. Nat. Microbiol. 6 (4), 425-442. doi: 10.1038/s41564-020-00854-z

Ardito, F., Giuliani, M., Perrone, D., Troiano, G., and Lo Muzio, L. (2017). The Crucial Role of Protein Phosphorylation in Cell Signaling and Its Use as Targeted Therapy. Int. J. Mol. Med. 40 (2), 271-280. doi: 10.3892/ijmm.2017.3036

Atayde, V. D., Aslan, H., Townsend, S., Hassani, K., Kamhawi, S., and Olivier, M. (2015). Exosome Secretion by the Parasitic Protozoan Leishmania Within the Sand Fly Midgut. Cell Rep. 13 (5), 957-967. doi: 10.1016/j.celrep.2015.09.058

Babatunde, K. A., Subramanian, B. Y., Ahouidi, A. D., Murillo, P. M., Walch, M., and Mantel, P.-Y. (2020). Role of Extracellular Vesicles in Cellular Cross Talk in Malaria. Front. Immunol. 11. doi: 10.3389/fimmu.2020.00022

Balmer, E. A., and Faso, C. (2021). The Road Less Traveled? Unconventional Protein Secretion at Parasite-Host Interfaces. Front. Cell Dev. Biol. 9, 662711. doi: $10.3389 /$ fcell.2021.662711

Bamra, T., Shafi, T., Das, S., Kumar, M., Dikhit, M. R., Kumar, A., et al. (2021). Leishmania Donovani Secretory Mevalonate Kinase Regulates Host Immune Response and Facilitates Phagocytosis. Front. Cell. Infect. Microbiol. 11, 641985. doi: $10.3389 /$ fcimb.2021.641985

Batty, M. B., Schittenhelm, R. B., Dorin-Semblat, D., Doerig, C., and GarciaBustos, J. F. (2020). Interaction of Plasmodium Falciparum Casein Kinase 1 With Components of Host Cell Protein Trafficking Machinery. IUBMB Life 72 (6), 1243-1249. doi: 10.1002/iub.2294

Bayer-Santos, E., Aguilar-Bonavides, C., Rodrigues, S. P., Cordero, E. M., Marques, A. F., Varela-Ramirez, A., et al. (2013). Proteomic Analysis of Trypanosoma Cruzi Secretome: Characterization of Two Populations of Extracellular Vesicles and Soluble Proteins. J. Prot. Res. 12 (2), 883-897. doi: 10.1021/pr300947g

Beer, K. B., and Wehman, A. M. (2017). Mechanisms and Functions of Extracellular Vesicle Release In Vivo-What We Can Learn From Flies and Worms. Cell Adhes. Migr. 11 (2), 135-150. doi: 10.1080/19336918.2016.1236899

Behnke, M. S., Fentress, S. J., Mashayekhi, M., Li, L. X., Taylor, G. A., and Sibley, L. D. (2012). The Polymorphic Pseudokinase ROP5 Controls Virulence in Toxoplasma parasites play in the subversion of host cell signalling will help uncover crucial drug targets.

\section{AUTHOR CONTRIBUTIONS}

AS and NR wrote the first draft of the manuscript. SS wrote sections of the manuscript. All authors contributed to manuscript revision, read, and approved the submitted version.

\section{FUNDING}

This work was funded by the French Government (Agence Nationale de la Recherche) Investissement d'Avenir programme, Laboratoire d'Excellence (LabEx) "French Parasitology Alliance For Health Care" (ANR-11-LABX-0024-PARAFRAP) and by the French government, ANR TEXLEISH (ANR-21-CE18-0026).

Gondii by Regulating the Active Kinase Rop18. PloS Pathog. 8 (11), e1002992. doi: 10.1371/journal.ppat.1002992

Beraki, T., Hu, X., Broncel, M., Young, J. C., O'Shaughnessy, W. J., Borek, D., et al. (2019). Divergent Kinase Regulates Membrane Ultrastructure of the Toxoplasma Parasitophorous Vacuole. P. Ntl. Acad. Sci. U. S. A. 116 (13), 6361-6370. doi: 10.1073/pnas.1816161116

Bisio, H., and Soldati-Favre, D. (2019). Signaling Cascades Governing Entry Into and Exit From Host Cells by Toxoplasma Gondii. Annu. Rev. Microbiol. Gottesman 73, 579-599. doi: 10.1146/annurev-micro-020518-120235

Boothroyd, J. C. (2013). Have It Your Way: How Polymorphic, Injected Kinases and Pseudokinases Enable Toxoplasma to Subvert Host Defenses. PloS Pathog. 9 (4), e1003296. doi: 10.1371/journal.ppat.1003296

Bradley, P. J., Ward, C., Cheng, S. J., Alexander, D. L., Coller, S., Coombs, G. H., et al. (2005). Proteomic Analysis of Rhoptry Organelles Reveals Many Novel Constituents for Host-Parasite Interactions in Toxoplasma Gondii. J. Biol. Chem. 280 (40), 34245-34258. doi: 10.1074/jbc.M504158200

Brandt, G. S., and Bailey, S. (2013). Dematin, a Human Erythrocyte Cytoskeletal Protein, Is a Substrate for a Recombinant FIKK Kinase From Plasmodium Falciparum. Mol. Biochem. Parasitol. 191 (1), 20-23. doi: 10.1016/j.molbiopara.2013.08.003

Brossas, J.-Y., Nicolas Gulin, J. E., Catalina Bisio, M. M., Chapelle, M., MarinachPatrice, C., Bordessoules, M., et al. (2017). Secretome Analysis of Trypanosoma Cruzi by Proteomics Studies. PloS One 12 (10), e0185504. doi: 10.1371/journal. pone.0185504

Buchholz, K. R., Bowyer, P. W., and Boothroyd, J. C. (2013). Bradyzoite Pseudokinase 1 Is Crucial for Efficient Oral Infectivity of the Toxoplasma Gondii Tissue Cyst. Eukaryotic Cell 12 (3), 399-410. doi: 10.1128/ec.00343-12

Butcher, B. A., Fox, B. A., Rommereim, L. M., Kim, S. G., Maurer, K. J., Yarovinsky, F., et al. (2011). Toxoplasma Gondii Rhoptry Kinase ROP16 Activates STAT3 and STAT6 Resulting in Cytokine Inhibition and Arginase-1-Dependent Growth Control. PloS Pathog. 7 (9), e1002236. doi: 10.1371/journal.ppat. 1002236

Carrera-Bravo, C., Koh, E. Y., and Tan, K. S. W. (2021). The Roles of ParasiteDerived Extracellular Vesicles in Disease and Host-Parasite Communication. Parasitol. Int. 83, e102373. doi: 10.1016/j.parint.2021.102373

Coffey, M. J., Sleebs, B. E., Uboldi, A. D., Garnham, A., Franco, M., Marino, N. D., et al. (2015). An Aspartyl Protease Defines a Novel Pathway for Export of Toxoplasma Proteins Into the Host Cell. Elife 4, e10809. doi: 10.7554/ eLife.10809

Colombo, M., Raposo, G., and Thery, C. (2014). Biogenesis, Secretion, and Intercellular Interactions of Exosomes and Other Extracellular Vesicles. Ann Rev. Cell Dev. Biol. 30, 255-289. doi: 10.1146/annurev-cellbio-101512-122326

Costa, R. W., da Silveira, J. F., and Bahia, D. (2016). Interactions Between Trypanosoma Cruzi Secreted Proteins and Host Cell Signaling Pathways. Front. Microbiol. 7, 388. doi: 10.3389/fmicb.2016.00388

Davies, H., Belda, H., Broncel, M., Ye, X., Bisson, C., Introini, V., et al. (2020). An Exported Kinase Family Mediates Species-Specific Erythrocyte Remodelling 
and Virulence in Human Malaria. Nat. Microbiol. 5 (6), 848-884. doi: 10.1038/ s41564-020-0702-4

de Koning-Ward, T. F., Gilson, P. R., Boddey, J. A., Rug, M., Smith, B. J., Papenfuss, A. T., et al. (2009). A Newly Discovered Protein Export Machine in Malaria Parasites. Nature 459 (7249), 945-U966. doi: 10.1038/nature08104

Diallo, M. A., Sausset, A., Gnahoui-David, A., Silva, A. R. E., Brionne, A., Le Vern, Y., et al. (2019). Eimeria Tenella ROP Kinase EtROP1 Induces G0/G1 Cell Cycle Arrest and Inhibits Host Cell Apoptosis. Cell. Microbiol. 21 (7), e13027. doi: $10.1111 / \mathrm{cmi} .13027$

Dlugonska, H., and Gatkowska, J. (2016). Exosomes in the Context of Toxoplasma Gondii - Host Communication. Ann. Parasitol. 62 (3), 169-174. doi: 10.17420/ ap6203.50

Donald, R. G. K., Zhong, T., Meijer, L., and Liberator, P. A. (2005). Characterization of Two T. Gondii CK1 Isoforms. Mol. Biochem. Parasitol. 141 (1), 15-27. doi: 10.1016/j.molbiopara.2005.01.011

Dorin-Semblat, D., Demarta-Gatsi, C., Hamelin, R., Armand, F., Carvalho, T. G., Moniatte, M., et al. (2015). Malaria Parasite-Infected Erythrocytes Secrete PfCK1, the Plasmodium Homologue of the Pleiotropic Protein Kinase Casein Kinase 1. PloS One 10 (12), e0139591. doi: 10.1371/journal.pone.0139591

Douanne, N., Dong, G., Douanne, M., Olivier, M., and Fernandez-Prada, C. (2020). Unravelling the Proteomic Signature of Extracellular Vesicles Released by Drug-Resistant Leishmania Infantum Parasites. PloS Neg. Trop. Dis. 14 (7), e0008439. doi: 10.1371/journal.pntd.0008439

Drewry, L. L., Jones, N. G., Wang, Q., Onken, M. D., Miller, M. J., and Sibley, L. D. (2019). The Secreted Kinase ROP17 Promotes Toxoplasma Gondii Dissemination by Hijacking Monocyte Tissue Migration. Nat. Microbiol. 4 (11), 1951-1963. doi: 10.1038/s41564-019-0504-8

Dubois, D. J., and Soldati-Favre, D. (2019). Biogenesis and Secretion of Micronemes in Toxoplasma Gondii. Cell. Microbiol. 21 (10), e13018. doi: 10.1111/cmi.13105

Dunn, P. P. J., Bumstead, J. M., and Tomley, F. M. (1996). Sequence, Expression and Localization of Calmodulin-Domain Protein Kinases in Eimeria Tenella and Eimeria Maxima. Parasitology 113, 439-448. doi: 10.1017/s0031182000081506

Etheridge, R. D., Alaganan, A., Tang, K., Lou, H. J., Turk, B. E., and Sibley, L. D. (2014). The Toxoplasma Pseudokinase ROP5 Forms Complexes With ROP18 and ROP17 Kinases That Synergize to Control Acute Virulence in Mice. Cell Host Microbe 15 (5), 537-550. doi: 10.1016/j.chom.2014.04.002

Fang, Y., He, X., Zhang, P., Shen, C., Mwangi, J., Xu, C., et al. (2019). In Vitro and In Vivo Antimalarial Activity of LZ1, A Peptide Derived From Snake Cathelicidin. Toxins 11 (7), 379. doi: 10.3390/toxins11070379

Fentress, S. J., and Sibley, L. D. (2011). The Secreted Kinase ROP18 Defends Toxoplasma's Border. Bioessays 33 (9), 693-700. doi: 10.1002/bies.201100054

Ferreira, E. R., Horjales, E., Bonfim-Melo, A., Cortez, C., da Silva, C. V., De Groote, M., et al. (2016). Unique Behavior of Trypanosoma Cruzi Mevalonate Kinase: A Conserved Glycosomal Enzyme Involved in Host Cell Invasion and Signaling. Sci. Rep. 6, 24610. doi: 10.1038/srep24610

Fleckenstein, M. C., Reese, M. L., Konen-Waisman, S., Boothroyd, J. C., Howard, J. C., and Steinfeldt, T. (2012). A Toxoplasma Gondii Pseudokinase Inhibits Host IRG Resistance Proteins. PloS Biol. 10 (7), e1001358. doi: 10.1371/journal.pbio. 1001358

Fleige, T., Fischer, K., Ferguson, D. J. P., Gross, U., and Bohne, W. (2007). Carbohydrate Metabolism in the Toxoplasma Gondii Apicoplast: Localization of Three Glycolytic Isoenzymes, the Single Pyruvate Dehydrogenase Complex, and a Plastid Phosphate Translocator. Eukaryotic Cell 6 (6), 984-996. doi: 10.1128/ec.00061-07

Fox, B. A., Rommereim, L. M., Guevara, R. B., Falla, A., Triana, M. A. H., Sun, Y., et al. (2016). The Toxoplasma Gondii Rhoptry Kinome Is Essential for Chronic Infection. Mbio 7 (3). doi: 10.1128/mBio.00193-16

Garg, M., Wahid, M., and Khan, F. (2020). Regulation of Peripheral and Central Immunity: Understanding the Role of Src Homology 2 Domain-Containing Tyrosine Phosphatases, SHP-1 \& SHP-2. Immunobiology 225 (1), 151847. doi: 10.1016/j.imbio.2019.09.006

Gualdron-Lopez, M., Flannery, E. L., Kangwanrangsan, N., Chuenchob, V., Fernandez-Orth, D., Segui-Barber, J., et al. (2018). Characterization of Plasmodium vivax Proteins in Plasma-Derived Exosomes From MalariaInfected Liver-Chimeric Humanized Mice. Front. Microbiol. 9, 1-15. doi: $10.3389 /$ fmicb.2018.01271

Han, H. Y., Zhu, S. H., Jiang, L. L., Li, Y., Dong, H., Zhao, Q. P., et al. (2013). Molecular Characterization and Analysis of a Novel Calcium-Dependent
Protein Kinase From Eimeria Tenella. Parasitology 140 (6), 746-755. doi: $10.1017 / \mathrm{s} 0031182012002107$

Hassani, K., Antoniak, E., Jardim, A., and Olivier, M. (2011). TemperatureInduced Protein Secretion by Leishmania Mexicana Modulates Macrophage Signalling and Function. PloS One 6 (5), e18724. doi: 10.1371/journal. pone. 0018724

Hiller, N. L., Bhattacharjee, S., van Ooij, C., Liolios, K., Harrison, T., LopezEstrano, C., et al. (2004). A Host-Targeting Signal in Virulence Proteins Reveals a Secretome in Malarial Infection. Science 306 (5703), 1934-1937. doi: $10.1126 /$ science.1102737

Hunter, C. A., and Sibley, L. D. (2012). Modulation of Innate Immunity by Toxoplasma Gondii Virulence Effectors. Nat. Rev. Microbiol. 10 (11), 766-778. doi: $10.1038 /$ nrmicro2858

Kats, L. M., Fernandez, K. M., Glenister, F. K., Herrmann, S., Buckingham, D. W., Siddiqui, G., et al. (2014). An Exported Kinase (FIKK4.2) That Mediates Virulence-Associated Changes in Plasmodium Falciparum-Infected Red Blood Cells. Int. J. Parasitol. 44 (5), 319-328. doi: 10.1016/j.ijpara.2014.01.003

Kolli, B. K., Kostal, J., Zaborina, O., Chakrabarty, A. A., and Chang, K.-P. (2008). Leishmania-Released Nucleoside Diphosphate Kinase Prevents ATP-Mediated Cytolysis of Macrophages. Mol. Biochem. Parasitol. 158 (2), 163-175. doi: 10.1016/j.molbiopara.2007.12.010

Krishnamurthy, G., Vikram, R., Singh, S. B., Patel, N., Agarwal, S., Mukhopadhyay, G., et al. (2005). Hemoglobin Receptor in Leishmania Is a Hexokinase Located in the Flagellar Pocket. J. Biol. Chem. 280 (7), 5884-5891. doi: $10.1074 /$ jbc.M411845200

Kulkarni, P. G., Shah, N., Waghela, B. N., Pathak, C. M., and Pappachan, A. (2019). Leishmania Donovani Adenylate Kinase 2a Prevents ATP-Mediated Cell Cytolysis in Macrophages. Parasitol. Int. 72, 101929. doi: 10.1016/j.parint. 2019.101929

Labbé, M., Peroval, M., Bourdieu, C., Girard-Misguich, F., and Pery, P. (2006). Eimeria Tenella Enolase and Pyruvate Kinase: A Likely Role in Glycolysis and in Others Functions. Int. J. Parasitol. 36 (14), 1443-1452. doi: 10.1016/j.ijpara.2006.08.011

Lal, K., Prieto, J. H., Bromley, E., Sanderson, S. J., Yates, J. R., Wastling, J. M., et al. (2009). Characterisation of Plasmodium Invasive Organelles; An Ookinete Microneme Proteome. Proteomics 9 (5), 1142-1151. doi: 10.1002/pmic. 200800404

Lanzer, M., Wickert, H., Krohne, G., Vincensini, L., and Breton, C. B. (2006). Maurer's Clefts: A Novel Multi-Functional Organelle in the Cytoplasm of Plasmodium Falciparum-Infected Erythrocytes. Int. J. Parasitol. 36 (1), 23-36. doi: 10.1016/j.ijpara.2005.10.001

Lee, W.-K., Ahn, H.-J., Baek, J.-H., Lee, C.-H., Yu, Y. G., and Nam, H.-W. (2014). Comprehensive Proteome Analysis of the Excretory/Secretory Proteins of Toxoplasma Gondii. B. Korean Chem. Soc. 35 (10), 3071-3076. doi: 10.5012/ bkcs.2014.35.10.3071

Liu, L., Tucker, S. C., and Satir, B. H. (2009). Toxoplasma PRP1 Is an Ortholog of Parafusin (PFUS) in Vesicle Scaffold Assembly in Ca2+-Regulated Exocytosis. Eur. J. Cell Biol. 88 (5), 301-313. doi: 10.1016/j.ejcb.2008.10.004

Li, Y., Xiu, F., Mou, Z., Xue, Z., Du, H., Zhou, C., et al. (2018). Exosomes Derived From Toxoplasma Gondii Stimulate an Inflammatory Response Through JNK Signaling Pathway. Nanomedicine 13 (10), 1157-1168. doi: 10.2217/nnm2018-0035

Lykins, J. D., Filippova, E. V., Halavaty, A. S., Minasov, G., Zhou, Y., Dubrovska, I., et al. (2018). CSGID Solves Structures and Identifies Phenotypes for Five Enzymes in Toxoplasma Gondii. Front. Cell. Infect. Microbiol. 8, 352. doi: 10.3389/fcimb.2018.00352

Mandacaru, S. C., Queiroz, R. M. L., Alborghetti, M. R., de Oliveira, L. S., de Lima, C. M. R., Bastos, I. M. D., et al. (2019). Exoproteome Profiling of Trypanosoma cruzi During Amastigogenesis Early Stages. Plos One 14 (11), e0225386. doi: 10.1371/journal.pone.0225386

Mantel, P.-Y., Hoang, A. N., Goldowitz, I., Potashnikova, D., Hamza, B., Vorobjev, I., et al. (2013). Malaria-Infected Erythrocyte-Derived Microvesicles Mediate Cellular Communication Within the Parasite Population and With the Host Immune System. Cell Host Microbe 13 (5), 521-534. doi: 10.1016/j.chom.2013. 04.009

Marino, N. D., Panas, M. W., Franco, M., Theisen, T. C., Naor, A., Rastogi, S., et al. (2018). Identification of a Novel Protein Complex Essential for Effector Translocation Across the Parasitophorous Vacuole Membrane of Toxoplasma Gondii. PloS Pathog. 14 (1), e1006828. doi: 10.1371/journal.ppat.1006828 
Marti, M., Good, R. T., Rug, M., Knuepfer, E., and Cowman, A. F. (2004). Targeting Malaria Virulence and Remodeling Proteins to the Host Erythrocyte. Science 306 (5703), 1930-1933. doi: 10.1126/science.1102452

Martin-Jaular, L., Nakayasu, E. S., Ferrer, M., Almeida, I. C., and del Portillo, H. A. (2011). Exosomes From Plasmodium yoelii-Infected Reticulocytes Protect Mice From Lethal Infections. Plos One 6 (10), e26588. doi: 10.1371/journal. pone.0026588

Mathieu, M., Martin-Jaular, L., Lavieu, G., and Thery, C. (2019). Specificities of Secretion and Uptake of Exosomes and Other Extracellular Vesicles for Cell-toCell Communication. Nat. Cell Biol. 21 (1), 9-17. doi: 10.1038/s41556-018-0250-9

Miranda, M. R., Canepa, G. E., Bouvier, L. A., and Pereira, C. A. (2008). Trypanosoma Cruzi Nucleoside Diphosphate Kinase 1 (TcNDPK1) has a Broad Nuclease Activity. Parasitology 135 (14), 1661-1666. doi: 10.1017/s0031182008005106

Montaner, S., Galiano, A., Trelis, M., Martin-Jaular, L., del Portillo, H. A., Bernal, D., et al. (2014). The Role of Extracellular Vesicles in Modulating the Host Immune Response During Parasitic Infections. Front. Immun. 5, 433. doi: 10.3389/fimmu.2014.00433

Moreira, D. S., and Murta, S. M. F. (2016). Involvement of Nucleoside Diphosphate Kinase B and Elongation Factor 2 in Leishmania Braziliensis Antimony Resistance Phenotype. Parasite Vector 9, 641. doi: 10.1186/s13071-016-1930-6

Nandan, D., Tran, T., Trinh, E., Silverman, J. M., and Lopez, M. (2007). Identification of Leishmania Fructose-1,6-Bisphosphate Aldolase as a Novel Activator of Host Macrophage Src Homology 2 Domain Containing Protein Tyrosine Phosphatase SHP-1. Biochem. Biophys. Res. Commun. 364 (3), 601607. doi: 10.1016/j.bbrc.2007.10.065

Nunes, M. C., Okada, M., Scheidig-Benatar, C., Cooke, B. M., and Scherf, A. (2010). Plasmodium Falciparum FIKK Kinase Members Target Distinct Components of the Erythrocyte Membrane. PloS One 5 (7), e11747. doi: 10.1371/journal.pone.0011747

Oakes, R. D., Kurian, D., Bromley, C., Ward, C., Lal, K., Blake, D. P., et al (2013). The Rhoptry Proteome of Eimeria tenella Sporozoites. Int. J. Parasitol. 43 (2), 181-188. doi: 10.1016/j.ijpara.2012.10.024

Ong, Y. C., Reese, M. L., and Boothroyd, J. C. (2010). Toxoplasma Rhoptry Protein 16 (ROP16) Subverts Host Function by Direct Tyrosine Phosphorylation of STAT6. J. Biol. Chem. 285 (37), 28731-28740. doi: 10.1074/jbc.M110.112359

Panas, M. W., Ferrel, A., Naor, A., Tenborg, E., Lorenzi, H. A., and Boothroyd, J. C. (2019). Translocation of Dense Granule Effectors Across the Parasitophorous Vacuole Membrane in Toxoplasma-Infected Cells Requires the Activity of ROP17, a Rhoptry Protein Kinase. mSphere 4 (4), e00276-00219. doi: 10.1128/ mSphere.00276-19

Peixoto, L., Chen, F., Harb, O. S., Davis, P. H., Beiting, D. P., Brownback, C. S., et al. (2010). Integrative Genomic Approaches Highlight a Family of ParasiteSpecific Kinases That Regulate Host Responses. Cell Host Microbe 8 (2), 208218. doi: 10.1016/j.chom.2010.07.004

Pereira, C. A., Bouvier, L. A., Camara, M.d. L.M., and Miranda, M. R. (2011). Singular Features of Trypanosomatids' Phosphotransferases Involved in Cell Energy Management. Enzyme Res. 2011, 576483-576483. doi: 10.4061/2011/576483

Queiroz, R. M. L., Ricart, C. A. O., Machado, M. O., Bastos, I. M. D., de Santana, J. M., de Sousa, M. V., et al (2016). Insight Into the Exoproteome of the Tissue-Derived Trypomastigote Form of Trypanosoma cruzi. Front. Chem. 4, 42. doi: 10.3389/ fchem.2016.00042

Rachidi, N., Knippschild, U., and Spath, G. F. (2021). Dangerous Duplicity: The Dual Functions of Casein Kinase 1 in Parasite Biology and Host Subversion. Front. Cell. Infect. Microbiol. 11, 655700. doi: 10.3389/fcimb.2021.655700

Ramirez-Flores, C. J., Cruz-Miron, R., Mondragon-Castelan, M. E., GonzalezPozos, S., Rios-Castro, E., and Mondragon-Flores, R. (2019). Proteomic and Structural Characterization of Self-Assembled Vesicles From Excretion/ Secretion Products of Toxoplasma gondii. J. Proteomics 208, 103490. doi: 10.1016/j.jprot.2019.103490

Regev-Rudzki, N., Wilson, D. W., Carvalho, T. G., Sisquella, X., Coleman, B. M., Rug, M., et al. (2013). Cell-Cell Communication Between Malaria-Infected Red Blood Cells via Exosome-Like Vesicles. Cell 153 (5), 1120-1133. doi: 10.1016/ j.cell.2013.04.029

Ribeiro, K. S., Vasconcellos, C. I., Soares, R. P., Mendes, M. T., Ellis, C. C., Aguilera-Flores, M., et al (2018). Proteomic Analysis Reveals Different Composition of Extracellular Vesicles Released by Two Trypanosoma cruzi Strains Associated With Their Distinct Interaction With Host Cells. J. Extracell. Vesicles 7 (1), 1463779. doi: 10.1080/20013078.2018.1463779
Ribeiro E Silva, A., Sausset, A., Bussiere, F. I., Laurent, F., Lacroix-Lamande, S., and Silvestre, A. (2021). Genome-Wide Expression Patterns of Rhoptry Kinases During the Eimeria Tenella Life-Cycle. Microorganisms 9 (8), 1621. doi: 10.3390/microorganisms 9081621

Saeij, J. P. J., Boyle, J. P., Coller, S., Taylor, S., Sibley, L. D., Brooke-Powell, E. T., et al. (2006). Polymorphic Secreted Kinases Are Key Virulence Factors in Toxoplasmosis. Science 314 (5806), 1780-1783. doi: 10.1126/science.1133690

Saito, T., Maeda, T., Nakazawa, M., Takeuchi, T., Nozaki, T., and Asai, T. (2002). Characterisation of Hexokinase in Toxoplasma Gondii Tachyzoites. Int. J. Parasitol. 32 (8), 961-967. doi: 10.1016/s0020-7519(02)00059-0

Severino, V., Farina, A., and Chambery, A. (2013). Analysis of Secreted Proteins. Method. Mol. Biol. (Clifton N. J.) 1002, 37-60. doi: 10.1007/978-1-62703-360-2_4

Siddiqui, G., Proellochs, N. I., and Cooke, B. M. (2020). Identification of Essential Exported Plasmodium Falciparum Protein Kinases in Malaria-Infected Red Blood Cells. Brit. J. Haematol. 188 (5), 774-783. doi: 10.1111/bjh.16219

Silverman, J. M., Chan, S. K., Robinson, D. P., Dwyer, D. M., Nandan, D., Foster, L. J., et al. (2008). Proteomic Analysis of the Secretome of Leishmania Donovani. Genome Biol. 9 (2), R35. doi: 10.1186/gb-2008-9-2-r35

Silverman, J. M., Clos, J., de'Oliveira, C. C., Shirvani, O., Fang, Y., Wang, C., et al. (2010a). An Exosome-Based Secretion Pathway Is Responsible for Protein Export From Leishmania and Communication With Macrophages. J. Cell Sci. 123 (6), 842-852. doi: $10.1242 /$ jcs.056465

Silverman, J. M., Clos, J., Horakova, E., Wang, A. Y., Wiesgigl, M., Kelly, I., et al. (2010b). Leishmania Exosomes Modulate Innate and Adaptive Immune Responses Through Effects on Monocytes and Dendritic Cells. J. Immunol. 185 (9), 5011-5022. doi: 10.4049/jimmunol.1000541

Silverman, J. M., and Reiner, N. E. (2011). Exosomes and Other Microvesicles in Infection Biology: Organelles With Unanticipated Phenotypes. Cell. Microbiol. 13 (1), 1-9. doi: 10.1111/j.1462-5822.2010.01537.x

Simpson, C., Jones, N. G., Hull-Ryde, E. A., Kireev, D., Stashko, M., Tang, K., et al. (2016). Identification of Small Molecule Inhibitors That Block the Toxoplasma Gondii Rhoptry Kinase Rop18. ACS Infect. Dis. 2 (3), 194-206. doi: 10.1021/ acsinfecdis.5b00102

Sisquella, X., Ofir-Birin, Y., Pimentel, M. A., Cheng, L., Abou Karam, P., Sampaio, N. G., et al. (2017). Malaria Parasite DNA-Harbouring Vesicles Activate Cytosolic Immune Sensors. Nat. Commun. 8, 1985. doi: 10.1038/s41467-01702083-1

Smirlis, D., Dingli, F., Pescher, P., Prina, E., Loew, D., Rachidi, N., et al. (2020). SILAC-Based Quantitative Proteomics Reveals Pleiotropic, Phenotypic Modulation in Primary Murine Macrophages Infected With the Protozoan Pathogen Leishmania Donovani. J. Proteomics 213. doi: 10.1016/ j.jprot.2019.103617

Smirlis, D., Dingli, F., Sabatet, V., Roth, A., Knippchild, U., Loew, D., et al. (2022). SILAKin: A Novel High Throughput SILAC and Mass Spectrometry-Based Assay to Identify the Substratome of Kinases Secreted by Pathogens. Front. Cell. Dev. Biol. 9, 800098. doi: 10.3389/fcell.2021.800098. 2005.2005.442720.

Sun, M., Liao, S., Zhang, L., Wu, C., Qi, N., Lv, M., et al. (2016). Molecular and Biochemical Characterization of Eimeria Tenella Hexokinase. Parasitol. Res. 115 (9), 3425-3433. doi: 10.1007/s00436-016-5104-4

Talevich, E., Mirza, A., and Kannan, N. (2011). Structural and Evolutionary Divergence of Eukaryotic Protein Kinases in Apicomplexa. BMC Evol. Biol. 11, 321. doi: 10.1186/1471-2148-11-321

Teng, F., and Fussenegger, M. (2021). Shedding Light on Extracellular Vesicle Biogenesis and Bioengineering. Adv. Sci. 8 (1), 2003505. doi: 10.1002/ advs. 202003505

Tomavo, S., Slomianny, C., Meissner, M., and Carruthers, V. B. (2013). Protein Trafficking Through the Endosomal System Prepares Intracellular Parasites for a Home Invasion. PloS Pathog. 9 (10), e1003629. doi: 10.1371/journal.ppat. 1003629

Torrecilhas, A. C., Soares, R. P., Schenkman, S., Fernandez-Prada, C., and Olivier, M. (2020). Extracellular Vesicles in Trypanosomatids: Host Cell Communication. Front. Cell. Infect. Microbiol. 10, 602502. doi: 10.3389/fcimb.2020.602502

Trocoli Torrecilhas, A. C., Tonelli, R. R., Pavanelli, W. R., da Silva, J. S., Schumacher, R. I., de Souza, W., et al. (2009). Trypanosoma Cruzi: Parasite Shed Vesicles Increase Heart Parasitism and Generate an Intense Inflammatory Response. Microbes Infect. 11 (1), 29-39. doi: 10.1016/j.micinf.2008.10.003

Venugopal, K., Chehade, S., Werkmeister, E., Barois, N., Periz, J., Lafont, F., et al. (2020). Rab11A Regulates Dense Granule Transport and Secretion During 
Toxoplasma Gondii Invasion of Host Cells and Parasite Replication. PloS Pathog. 16 (5), e1008106. doi: 10.1371/journal.ppat.1008106

Vincensini, L., Richert, S., Blisnick, T., Van Dorsselaer, A., Leize-Wagner, E., Rabilloud, T., et al. (2005). Proteomic Analysis Identifies Novel Proteins of the Maurer's Clefts, A Secretory Compartment Delivering Plasmodium falciparum Proteins to the Surface of Its Host Cell. Mol. Cell. Proteom. 4 (4), 582-593. doi: 10.1074/mcp.M400176-MCP200

Wang, Z., Huang, B., Dong, H., Zhao, Q., Zhu, S., Xia, W., et al. (2016a). Molecular Characterization and Functional Analysis of a Novel Calcium-Dependent Protein Kinase 4 From Eimeria Tenella. PloS One 11 (12), e0168132. doi: 10.1371/journal.pone.0168132

Wang, Z., Wang, S., Wang, W., Gu, Y., Liu, H., Wei, F., et al. (2016b). Targeted Disruption of CK1 Alpha in Toxoplasma Gondii Increases Acute Virulence in Mice. Eur. J. Protistol. 56, 90-101. doi: 10.1016/j.ejop.2016.07.006

Ward, P., Equinet, L., Packer, J., and Doerig, C. (2004). Protein Kinases of the Human Malaria Parasite Plasmodium Falciparum: The Kinome of a Divergent Eukaryote. BMC Genomics 5. doi: 10.1186/1471-2164-5-79

Wowk, P. F., Zardo, M. L., Miot, H. T., Goldenberg, S., Carvalho, P. C., and Moerking, P. A. (2017). Proteomic Profiling of Extracellular Vesicles Secreted From Toxoplasma Gondii. Proteomics 17 (15-16), 1600477. doi: 10.1002/ pmic. 201600477

Xu, P., Ianes, C., Gaertner, F., Liu, C., Burster, T., Bakulev, V., et al. (2019). Structure, Regulation, and (Patho-)Physiological Functions of the StressInduced Protein Kinase CK1 Delta (CSNK1D). Gene 715, 144005. doi: 10.1016/j.gene.2019.144005

Yamamoto, M., Standley, D. M., Takashima, S., Saiga, H., Okuyama, M., Kayama, H., et al. (2009). A Single Polymorphic Amino Acid on Toxoplasma Gondii
Kinase ROP16 Determines the Direct and Strain-Specific Activation of Stat3. J. Exp. Med. 206 (12), 2747-2760. doi: 10.1084/jem.20091703

Yu, H., Rao, X., and Zhang, K. (2017). Nucleoside Diphosphate Kinase (Ndk): A Pleiotropic Effector Manipulating Bacterial Virulence and Adaptive Responses. Microbiol. Res. 205, 125-134. doi: 10.1016/j.micres.2017.09.001

Zhong, W., Li, K., Cai, Q., Guo, J., Yuan, M., Wong, Y. H., et al. (2020). Pyruvate Kinase From Plasmodium Falciparum: Structural and Kinetic Insights Into the Allosteric Mechanism. Biochem. Bioph. Res. Commun. 532 (3), 370-376. doi: 10.1016/j.bbrc.2020.08.048

Conflict of Interest: The authors declare that the research was conducted in the absence of any commercial or financial relationships that could be construed as a potential conflict of interest.

Publisher's Note: All claims expressed in this article are solely those of the authors and do not necessarily represent those of their affiliated organizations, or those of the publisher, the editors and the reviewers. Any product that may be evaluated in this article, or claim that may be made by its manufacturer, is not guaranteed or endorsed by the publisher.

Copyright (C) 2022 Silvestre, Shintre and Rachidi. This is an open-access article distributed under the terms of the Creative Commons Attribution License (CC BY). The use, distribution or reproduction in other forums is permitted, provided the original author(s) and the copyright owner(s) are credited and that the original publication in this journal is cited, in accordance with accepted academic practice. No use, distribution or reproduction is permitted which does not comply with these terms. 